\title{
Importance of acknowledging racial and cultural differences
}

\author{
Please don't let me be misunderstood
}

\author{
Xavier Coll
}

\begin{abstract}
It is important to explore and interpret the dynamics of cultural differences and racism in clinical work. Race and culture often play a significant role in any psychotherapeutic relationship. Vignettes and clinical narratives are used to illustrate that they can be a useful vehicle for the expression of transferences, demonstrating how basic concepts of psychotherapy apply to crosscultural interactions.
\end{abstract}

"Long before Horret Campbell was arrested, long before his description or picture was circulated. I guessed he would be black, ... Campbell set about a group of toddlers with a $2 \mathrm{ft}$ machete because he thought they were 'little devils'. He heard their voices taunting him calling him 'nigger'" (Victor, 1996).

The word ethnology refers us back to the science of race, and traditionally the description of the superficial physical characteristics, the ways of life, and modes of thought, of the distinctive types of man (New Caxton Encyclopedia, 1977). The original idea of a 'race' was nearer to that of a nation than to a biological unit or complex. Culture, defined as a system of beliefs, values, and behavioural patterns, plays an important role in psychotherapy. Culture, a concept established by Edward Tylor, who took the term from German social thinkers in his famous definition "Culture (or civilization) . . . is that complex whole which includes knowledge, belief, art. custom, and other capabilities and habits acquired by man as a member of society", was developed mainly by anthropologists and ethnologists, but used and experienced by all of us (New Caxton Encyclopedia, 1977). Racism can be understood as an inability to accept and acknowledge differences of race. It might involve the treatment of some people as inferior because they belong to a particular race, and it is usually used to demonstrate disapproval. Where racism is present, there is an attempt to control and dominate the object that is felt to be different and separate. Ideas of White supremacy form part of the fabric of many societies, and play a part in the way that White people relate to non-White people. The working through of issues of racism seems to be relatively unimportant for the trainee in psychiatry. I believe it has proved difficult for the College to deal with this issue, perhaps because trainees and supervisors alike have little awareness of the significance of race and racism in the therapeutic process.

Psychotherapy is about human relationships, having also a component of foreignness, where both patient and therapist bring with them their own prejudices from their respective cultures (Kareem \& Littlewood, 1992). Foreigners, in particular, have to negotiate themselves through the maze of covert and even overt prejudices and discriminations. The experience of these prejudices, which may be real or imagined (via projection or projective identification), leads to a difficulty in assessing the situation realistically. The ability to contain and make sense of these feelings is essential to rational functioning. Unlike the external world, the prejudices of patients have to be explored as they might be the very defences that prevent them from benefiting from treatment.

\section{Managing complicated transactions}

Miss A. was a 35-year-old single woman with a long history of anorexia nervosa, who attended an out-patient clinic to see a young non-British born psychiatric registrar. Initially, things were going well: good therapeutic alliance, good rapport, good attendance. "You are doing well", the supervisor said. After five months of seeing the trainee on a two-weekly basis, the frequency of the meetings was spread out. The foreign registrar began to hear a rumour that Miss A. no longer wanted to see him. Interestingly, the path that this information follows can be rather variable. It might travel from the receptionist to the consultant, via a letter (often written by the client and signed by a submissive boyfriend, mother, or father), a caring occupational therapist, a colluding secretary, or even a multifunctional domestic. Sure enough, two weeks later, the consultant informed the registrar that Miss A. no longer wanted to see him because she 
could not understand him. By then, the trainee was probably feeling rather vulnerable, beginning to doubt in his abilities, with the situation being both distressing for him and detrimental to his other patients. It is important to understand what happened. Clearly, there was more than one possible reading. First, the more concrete interpretation: "She does not understand the trainee because his English is not good enough to be a psychiatrist in England". While possible, this is highly unlikely as he had already been working with this client for several months, and is understood by other patients and colleagues. Why, in these situations, do only the complaints seem to count? Second, a more likely hypothesis is that this complaint is an expression of the client feeling confused and misunderstood. The foreign therapist becomes the perfect recipient of anger, so that 'I don't want to know' and 'it is painful', are easily translated into 'I can not understand him'. The part of the patient that does not feel understood can easily be projected into the therapist. In this instance, the consultant responded appropriately by offering a place and a time to talk. Both the registrar and Miss A. benefited from this. Once she was aware that she was making the foreign doctor a scapegoat, it was possible to work through these feelings, and Miss A. managed to move on, while the trainee felt understood, supported, and was able to learn by this excellent example of the management of complicated transactions (Norton \& Smith, 1994).

\section{Racial transference among non-racists}

A middle-aged White civil servant who prided himself on being racially aware and whose work brings him in constant contact with members of the Afro-Caribbean community, was referred to an Asian therapist for treatment. Mr B. felt that the therapist was just as racially aware and open minded as he was, and that the obvious racial difference between them was not an issue. He was having difficulties in his relationship with his girlfriend, as well as feeling low, tense and anxious. Coming to the foreign and non-White therapist for treatment, gave him a sense of validity, and reinforced his denial of any racial feelings. These created an ideal space for projections into the therapist of the unwanted parts of himself. After three months of weekly sessions, Mr B. complained of being stuck in both his work and his therapy. He felt frustrated with his work because he was made to feel helpless by his clients, because of their lack of understanding of the English language and way of life. He was contemplating terminating therapy as "it was not doing him any good". The therapist' countertransference feelings matched those of the client.
He too was feeling extremely frustrated, and felt unable to understand $\mathrm{Mr}$ B.'s unconscious communication. Mr B. was, at a deeper level, aware of the differences with the therapist, which he could not face. This awareness once made conscious, gave him the opportunity to acknowledge the therapist as being in possession of some goodness, in having the ability to contain his fantasies without being hurt. This credibility in the therapist and the therapy is a central factor in psychological healing. This is a cultural factor. Credibility of psychotherapeutic rationales depends to a large extent on the acquaintance of the general public with the set of ideas used in therapy. For instance, 'talking helps', 'behaviour is mostly learned and can be changed by relearning', and 'emotions that are not expressed cause sickness' are all beliefs, typical of the western middle class. They are not shared by, and probably also not true for people outside this particular culture or subculture. Talking about one's emotions, which is encouraged in most western therapies, is considered harmful to mental health in many non-western cultures (Kleinman \& Good, 1985).

\section{Racism and cultural differences for children}

Islam was nine years old when he was referred for individual therapy by his school doctor. The school was concerned by his lack of progress, his inability to make friends, and his tendency to 'opt out'. His parents had been living in England for several years, but spoke no English, and lived and worked among their close knit community. They were very concerned about their son and felt lost as to how to help him. Islam was very curious about the therapist's origins. He looked at him and said "you are not Egyptian but you are not English" and demanded to know where the therapist came from. Islam looked at the therapist seriously and then said that at school sometimes they called him 'Paki'. He looked at his dark hands and shouted "I am not a Paki, those boys are nasty to Pakis". This boy was unusually open and he verbalised his anxieties about the therapist, who represented someone alien to him, arousing his own feelings of being an outsider, and his confusion at being an Egyptian child brought up in England. Islam had never been to an English household. He said that "he didn't want to anyway, because English mums feed their children junk food, and then throw them out". Difference in cultures can be a good vehicle into which our bad and good feelings are projected. This is also used by parents, to safeguard their idealised own culture. The more frightened and threatened a minority culture feels from the majority culture, the more 
protective and enclosed it becomes, keeping the 'bad' influence (English in the case of Islam), outside. Unless children are helped to understand both their native culture, and the culture where they are living, they might face unnecessary conflicts with their therapist's values, and the values of the society where they live (Kareem \& Littlewood, 1992).

\section{Problems with administrative stafi}

She was, sometimes, an efficient secretary, also showing remarkable skills in diverting work to other people, and being superficially helpful when she needed to be. To her, things were not good enough if they were not 'British made'. Doctor X. was neither born nor bred in the United Kingdom, although, she had proved that she was up to British standards, after several years of training and passing her exams in England. After a year of working in the department, and while she was on holiday, the secretary said to the consultant that she was editing Dr X.'s letters, to make them understandable. Dr X. sensed a 'strange atmosphere' and brought up the subject on the next supervision session. A meeting was suggested by the supervisor, with the secretary, consultant and Dr $X$. present. The secretary was very reluctant (even though it would not represent extra work), but finally agreed to print both the 'laughable letter, and the amended one. Over the next three months, only one draft was received, in which two words were changed for a synonym. Dr X. was encouraged to think that this had not been a personal vendetta by a racist secretary, but, deep inside, she knew that her successor, who was also a foreign trainee could also have her work, efforts and hopes undermined. The fundamental narcissistic issue of unspoken cultural, ethnic, and racial prejudices is vital to comprehend the difficulties and the pain that $\mathrm{Dr} \mathrm{X}$. encountered.

\section{Conclusions}

"Am I being too sensitive, are these things really happening? Where does awareness end and paranoia begin? Without the privileges I enjoy, would I even now be in a secure mental home? Or would I be heading for a local school, clutching a machete, like Horret Campbell?" (Victor, 1996).

The clinical narratives demonstrate that racial differences are important in psychotherapeutic relationships. As a psychiatrist, it is vital to see behind provocative or difficult behaviour, establishing a good therapeutic alliance with the patient. Not using one's mother tongue to communicate with our patients can be like participating in a pilot study of feedback all the time, having subtle effects on the behaviour of doctors during consultations. It leads them to be even more aware of the need to ensure that patients properly understood what they were saying. Shame still abounds concerning our lack of awareness of racial and cultural differences. This is a specific example of the importance of the differences that needs to be highlighted in view of its commonplace occurrence. By being aware of these differences, we can spare ourselves a painful struggle and avoid undermining our therapeutic efficacy (Holmes, 1992). I believe it has been difficult for the College to deal with this issue, however, one feels hopeful as there have recently been moves in this field, which include the recent Council Report CR48 (The Royal College of Psychiatrists, 1996) and the initiatives undertaken by the Transcultural Psychiatry Special Interest Group over recent months.

\section{Acknowledgements}

I am grateful to Drs Jeremy Holmes, Glen Roberts, Isabel Casson and Fergus Law, and to both Elaine Cronk and Katrina Haye for their encouragement and comments on the manuscript.

\section{References}

Holmes, D. E. (1992) Race and transference in psychoanalysis and psychotherapy. International Journal of Psychoanalysis, 73, 1-11.

KAREEM, J. \& LITTLWOOD, R. (1992) Intercultural Therapy: Themes, Interpretations and Practice. Oxford: Blackwel Scientific Publications.

KLEINMAN, A. \& GOOD. B. (1985) Culture and Depression Studies in the Anthropology and Cross-Cultura Psychiatry of Affective Disorder. London: California Press.

NoRTON, K. \& SMrrH, S. (1994) Problems with Patients Managing Complicated Transactions. Cambridge: Cambridge University Press.

NEw CAXTON ENCYCLOPEDIA (1977) The New Caxton Encyclopedia. Volume 7. p. 2249. London: Caxton Publishing Company Limited.

ROYAL COLLEGE OF PSYCHIATRISTS (1996) Report of the Working Party to Review Psychiatric Practices and Training in a Multi-Ethnic Society (Council Report CR48). London: Royal College of Psychiatrists.

VicToR, P. (1996) Driven mad by racial abuse. Independent, 11 December, p. 15

Xavier Coll, Senior Registrar in Child and Adolescent Psychiatry, Bursledon House, 119 Tremona Road, Southampton University Hospitals NHS Trust, Southampton SO16 6HU 